\title{
NUTRITION IN PEDIATRIC ONCOLOGY A PROSPECTIVE STUDY
}

\author{
S.Aggoune (1); C. Benkhelil (2) ; N. Bouterfas(3) ; A.Bitam(4) ; M.Lamri (5)
}

(1) Pediatric Department.EPH Belfort

$(2,4)$ : Laboratory of food technology and human nutrition, health nutrition biology team, National School of Agronomy El Harrach.

(3) Pediatric Department A CHU Beni Messous.

(4) CPMC Biochemistry Laboratory

The term "childhood cancers" refers to all malignant tumors occurring in children under 15 years of age. In 2013, nearly 908 cases were diagnosed on the national territory.

The cancer and its treatment are accompanied by variable: a reduction in food consumption, an increase in energy expenditure and various metabolic and functional disturbances. The whole is therefore a situation of high nutritional risk in children. This most often results in progressive protein-energy malnutrition combined with deficiencies in different nutrients. This increases the morbidity and mortality associated with the disease, while threatening growth..

a prospective study was interested 100 children (6 months-15 years) with cancer, treated in the wilaya of Algiers (1 pediatric oncology unit and 4 units) from $1^{\text {st }}$ of December 2015 to $15^{\text {th }}$ of May 2016. Among the 100 children, $40 \%$ are underweight, 29\% stunted, 37\% wasted and $37 \%$ undernourished more or less pronounced depending on the level of pre-albumin $(<0 \%) .14 \mathrm{~g} / \mathrm{L}$ ), while $23 \%$ were overweight or obese.
The factor that significantly $(p<0.01)$ influenced the onset or development of malnutrition in pediatric oncology was found to be the nature of neoplastic pathology.

Several factors can influence the assessment of nutritional status in pediatric oncology including: the heterogeneity of the sample, the individual's sensitivity to malnutrition and anti-cancer regimes, sensitivity and tolerance treatments and the markers and criteria used for its evaluation. In our study, the prevalence of undernutrition, whatever its intensity, is estimated at between 16 and $40 \%$. Nutritional intervention must be an integral part of the overall therapeutic project of the child; Especially since we are talking to growing organisms, and the therapeutic protocols are often aggressive. Ideally, every child should have a nutritional assessment early on after the diagnosis has been announced to quickly adapt the management. The latter aims to ensure the qualitative and quantitative nutritional intake necessary for specific needs and to reduce the side effects of chemotherapy.

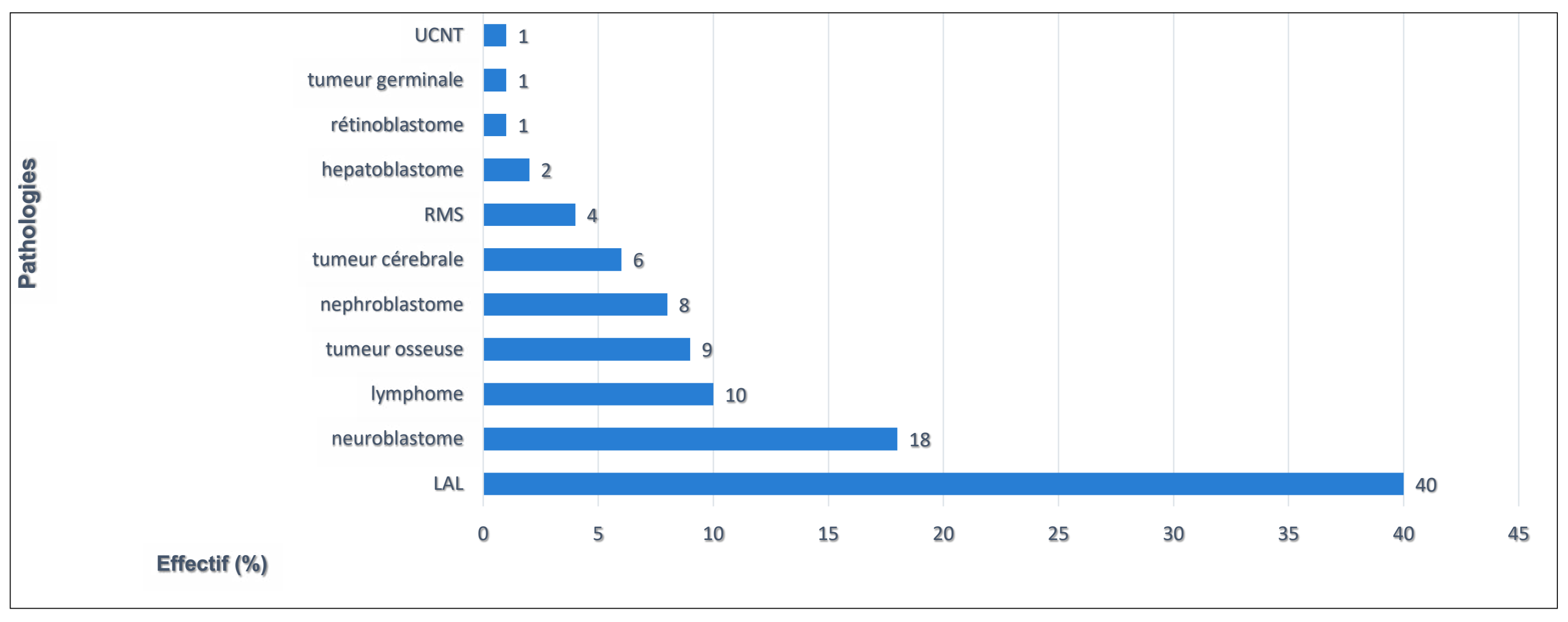

Distribution according to pathology

\section{Bibliography}

1. Boisson M and al La dénutrition liée à la maladie cancéreuse chez l'enfant. J de Pharmacie Clinique, 2012. 31(1), 27-49.

2. Khelafi N. Epidémiologie des cancers de l'enfant et place des LAL: congrès national de pédiatrie, 35émeEdition, Alger, décembre 2014.

3. Ladas E.J and al.. A Multidisciplinary Review of Nutrition Considerations in the Pediatric Oncology Population : A Perspective From Children's Oncology Group. Nutrition in Clincal Practice, 2005. 20(4), 377-393.

4. Lemos, $P$ and al.. Nutritional status of children and adolescents at diagnosis of hematological and solid malignancies. Brazilian J Hematology \& Hemotherapy, 2014. 36(6), 420-423. 